\title{
Jobotifetime
}

\section{Technology and team work}

$\mathrm{I}_{\mathrm{r}}^{\mathrm{t}}$ f you love working with technology and people, then serving as the Web site and virtual library coordinator at Western Kentucky University (WKU) Libraries might be your job of a lifetime. Haiwang Yuan has held that position since 1998.

\section{Defining moment}

When Yuan began, the position was brand new and the use of the Internet in libraries was taking off. He recalled, "The dean of libraries had created this new position, but I had to create what I was going to do. I had a blank ticket and at first a lot of

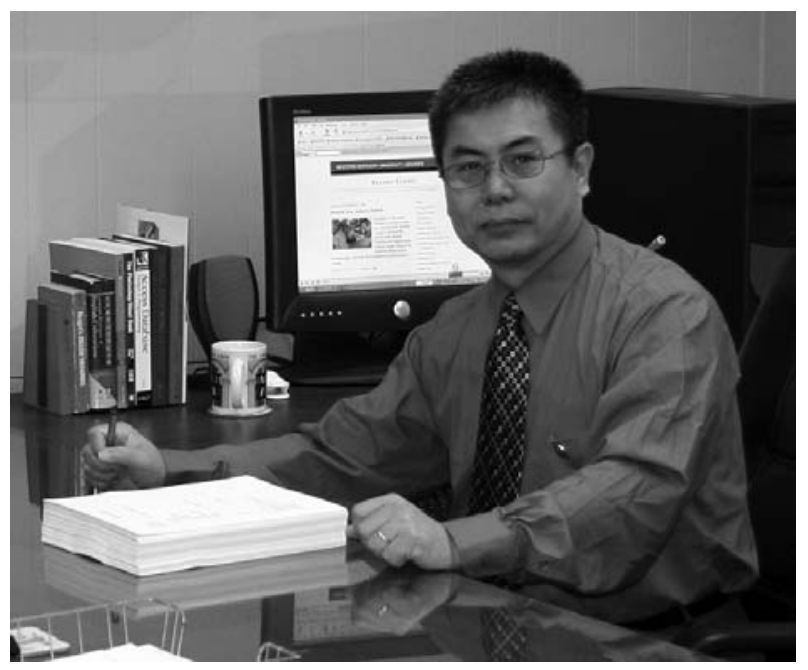

unit. When I was charged with creating a portal, not all the team members were enthusiastic. (People are sometimes fearful of new technology at first). Nonetheless, I had to do it because I had been given this charge. I had to find a way to get people interested. The portal was not a techie thing; it was not database driven, but rather a method of organizing the content. So after we established categories, I gave each member several areas for which to select Web sites. That's Haiwang Yuan is the Web site and virtual library coor- how we got things dinator at Western Kentucky University Libraries. moving." The repeople were doubtful. 'What is Haiwang doing in there, twiddling his thumbs?' I laid out how I would develop, design, and maintain the Web site of the WKU Libraries. Then I created a plan and a timeline, including what day I was going to finish what. When they found out all that was involved, the question changed to, 'does he sleep?'”

\section{Team with a capital T}

Yuan spoke very warmly about the 14 member Web Site Team (WST), whose work he coordinates. "The members of the Web site team came from different units by design, so they could serve as liaisons with that sulting Topper InfoPortal was an early example of the use of a portal for an academic library Web site.

\section{Get them involved}

Yuan shared the following lessons learned. "No matter how hard you work or how well you may think you have designed a Web site, if you don't involve the people, they may not like it. One lesson I learned is how

Danianne Mizzy is assistant head of the Engineering Library at the University of Pennsylvania. Have an idea for a "Job of a Lifetime" story? E-mail: danianne@seas. upenn.edu. 
best to get them involved. Early on, when I wanted to put in a new color, I let the whole library vote to select it. The dean said, 'Ours is not a democracy, it's a bureaucracy.' So WST worked out the procedures, policies, and guidelines we now follow in the design process."

\section{A person's person}

When I asked Yuan what qualities were important for someone in his job, I was surprised by his emphasis on the so-called "soft skills," which he termed being a "person's person." "Of course, I have to be well-trained in Web design and development and have the technology know-how. The dean is very supportive of me and sends me to many professional workshops. Then I became the trainer who trained the whole team. You have to be willing to share with your team members. That way you can delegate. If they don't have the know-how, you can't ask them to do it."

\section{Web site and virtual library coordinator}

What: Western Kentucky University Libraries

Where: Bowling Green, Kentucky

For more information, visit: www.wku.edu/Library/

\section{Bridging two cultures}

Yuan is very committed to promoting diversity. As a bilingual Chinese American librarian who understands both cultures, he has positioned himself as a cultural bridge. This has taken many different forms over the years: creating an extensive Web site about China, teaching Chinese 101, contributing extensively to an encyclopedia about contemporary Chinese culture, and helping establish an academic exchange program between WKU and Chongqing University of Technology and Business.

Yuan recounted his newest effort. "I'm writing a book, Tales of the Han Chinese, to be published by Libraries Unlimited next year. It's my baby. This past summer I went to China from May 18 to July 25 collecting stories from traditional storytellers that I am transcribing and retelling. I applied for and received a summer faculty scholarship for $\$ 3,000$ to cover my travel expenses. The university, the library

Yuan expanded on his view of the importance of good personal relations in the workplace.

"Personal relations are a learning process. It's like honing a tool. I may be a nice person, but being nice is not everything. You still need a lot of skills. For that I also went to workshops. The dean was a mentor to me and taught me a lot. For instance, he gave me a copy of Dale Carnegie's How to win friends and influence people. I learned how to delegate, that there's a give and take, ups and downs, but not to take things personally. And it is very important to share the credit with the team. Appreciate all the help and all the initiatives of your team members. No matter how hard you work, you cannot accomplish the job without their hard work and participation. For this job know-how, good people skills, and good administrative organizational skills are essential." administrators, and my fellow faculty were all so supportive."

\section{No rest for the technologist}

When I interviewed Yuan, he had just returned from the Kentucky Library Association conference. He was excited about some new Web design methods employed by the University of Kentucky and about user testing that can track people's eye movements to see where they go on the page. The very next day, he and a colleague were off to attend Information Today's "Blog University" workshop. Flash forward a few weeks to the picture on the previous page. On his desk is the newly completed manuscript of Tales of the Han Chinese and on the screen of his computer is the new University Library Blog. Bridging cultures and deploying new technologies are all in a day's work for Haiwang Yuan. z 